\title{
Has HSR improved territorial cohesion in Spain? An accessibility analysis of the first 25 years: 1990-2015
}

\author{
Andres Monzon (1D), Elena Lopez and Emilio Ortega \\ Transport Research Centre (TRANSyT), Universidad Politecnica de Madrid, Madrid, Spain
}

\begin{abstract}
High Speed Rail (HSR) in Spain began in 1992 and currently has a network of some $3200 \mathrm{~km}$. In this 25-year period, accessibility has progressively increased, changing its spatial distribution throughout the country. However, improvements in the HSR network may or may not have contributed to a more balanced territorial distribution of accessibility levels. These distributional effects of HSR have important implications for territorial cohesion, which is a strategic planning goal for transport infrastructures in the European Union. This paper presents a methodology for evaluating 'accessibility-based' territorial cohesion effects of HSR corridors. Accessibility values are calculated for successive fiveyear periods. Territorial cohesion effects are assessed based on changes in accessibility patterns and their spatial distribution. The results show that new HSR lines have significantly increased the accessibility levels of the Spanish population to most destinations. On average accessibility values have improved in the 1990-2015 period by $48.6 \%$ due to HSR, with differences among locations depending if they are or not nodes of the HSR network. The study's findings show also a more balanced distribution of accessibility, with $15 \%$ reduction in the dispersion of accessibility values between 1990 and 2015, implying a positive contribution to territorial cohesion goals.
\end{abstract}

\section{KEYWORDS}

High speed rail (HSR); accessibility; territorial cohesion; GIS

\section{Introduction}

The development of a European high speed rail (HSR) network was established as a goal in the 2011 European Union's White Paper on Transport:

By 2050, complete a European high-speed rail network. Triple the length of the existing highspeed network by 2030 and maintain a dense railway network in all Member States. By 2050, the majority of medium-distance passenger transport should go by rail. (EC, 2011)

HSR networks are valued as essential assets for enhancing connectivity between cities, and their associated accessibility improvement is frequently assumed to trigger spatial, social, land-use and economic development processes, which may potentially contribute to the reduction of regional disparities and the achievement of territorial cohesion goals (Garmendia, Ribalaygua, \& Ureña, 2012; Givoni, 2006; González-González \& Nogués, 2016; Jacobs-Crisioni et al., 2016; Peters, 2003). 
In contrast, and as recently brought up by a report of the European Court of Auditors (European Union, 2018), instead of a European HSR network, reality shows an 'ineffective patchwork' of HSR links, mainly due to the fact that investment decisions are 'often based on political considerations, and cost- benefit analyses are not used generally as a tool to support cost-efficient decision-making.' (European Union, 2018, p. 8). Some authors even include HSR projects in the 'megaprojects phenomenon' (Flyvbjerg, Bruzelius, \& Rothengatter, 2003), alerting the appearance of systematic appraisal biases - an 'appraisal optimism' (Preston, 2009)-, mainly as underestimated costs, over prediction of traffic volumes and overvalued benefits (Beria, Grimaldi, Albalate, \& Bel, 2018; Crozet, 2014). In addition, many unresolved research issues remain on the assumed wider economic benefits of HSR (Barrón et al., 2012; Campos \& de Rus, 2009; de Rus, 2011; Nash, 2015; Preston, 2009; Vickerman, 2015a; Vickerman \& Ulied, 2009), increasing the controversy on the efficacy of the allocation of such important amounts of public resources to certain HSR investments, with the consequent burden to Governments and taxpayers.

From the basis of this complex picture, this paper focuses in the analysis of HSR impacts from a spatial perspective, based in the evaluation of how a new HSR link changes the spatial distribution of accessibility, which may lead either to a more balanced or polarized distribution. Indeed, the risk of HSR to increase regional disparities and reinforce existing core-periphery patterns is a major research issue (Garmendia et al., 2012; Malecki, 2014; Martínez Sanchez-Mateos \& Givoni, 2012; Monzón, Ortega, \& López, 2013; Ureña, Menerault, \& Garmendia, 2009; Vickerman, 2015b). HSR networks tend to be primarily planned to efficiently interconnect major economic hubs, leading to agglomeration effects in locations near HSR stations. A number of research works have proposed methodologies to assess these polarizing impacts; based on the analysis of changes in the spatial distribution of accessibility induced by new HSR links, mostly at strategic macro levels, mainly international or national (Bröcker, Korzhenevych, \& Schürmann, 2010; Jacobs-Crisioni et al., 2016; López, Gutiérrez, \& Gómez, 2008; Monzón et al., 2013).

These concerns are related to the territorial cohesion concept, understood as

a process of promoting a more cohesive and balanced territory, by: (i) supporting the reduction of socioeconomic territorial imbalances; (ii) promoting environmental sustainability; (iii) reinforcing and improving the territorial cooperation/governance processes; and (iv) reinforcing and establishing a more polycentric urban system. (Medeiros, 2016)

Indeed, the aforementioned spatially polarizing impacts induced by transport infrastructure are frequently assumed to have a negative effect on territorial cohesion or territorial equity objectives (Bröcker et al., 2010; González-González \& Nogués, 2016; Jacobs-Crisioni et al., 2016; Naranjo Gómez, 2016; Peters, 2003; van Wee \& Geurs, 2011).

The rationale in this paper is that the degree of equality resulting from the spatial distribution of accessibility after building a new HSR link provides information on its potential contribution to territorial cohesion objectives. The aim of this research is to assess the impacts of new HSR links on this 'accessibility-based' territorial cohesion. From this rationale, this paper addresses the territorial cohesion issue in the case study of the HSR network development in Spain in the period between 1990 and 2015. The paper develops an accessibility-based methodological approach (López et al., 2008; Ortega, López, \& Monzón, 2012, 2014). The evolution of the territorial distribution of accessibility 
indicators is assessed in different horizon years, namely 1990, 1995, 2000, 2005, 2012 and 2015. The rationale of this approach is to study not only the global effect in the 1990-2015 period, but also the evolution of 'accessibility-based' territorial cohesion values throughout the different stages of development of the Spanish HSR network.

The structure of the paper is as follows. The section following this introduction includes a brief research background on the topic. Section 3 describes our methodological approach. The analysis and results of the Spanish case study are included in Section 4. Finally, Section 5 contains the concluding remarks of the research.

\section{Background: accessibility and territorial cohesion}

Territorial cohesion was officially added to the EU's social and economic cohesion objectives in the Lisbon Treaty of 2007, although it was first mentioned two decades earlier in the European Spatial Development Perspective (ESDP) (CEC, 1999). Territorial cohesion is a complex, multidimensional and dynamic concept, for which there is still no agreed definition. The term has been approached from many different perspectives both in EU documents (CEC, 1999, 2008) and in the scientific literature (Clifton, Díaz-Fuentes, \& Fernández-Gutiérrez, 2016; Davoudi, 2005; Faludi, 2004, 2006; Medeiros, 2016).

Transport policy is one of many sectoral policies acknowledged to contribute to territorial cohesion objectives (CEC, 2008), as it helps connect territories and enhance accessibility by providing access to quality public infrastructure services (Clifton et al., 2016; Malý, 2016). Recent research in transport-related studies places special focus on how improvements in transportation networks influence the territorial distribution of the quality of this access to desired destinations. This distribution is frequently supported by calculating accessibility indicators.

From a spatial perspective, accessibility constitutes a feature of a given location, related to the ease with which 'desired' destinations can be reached from it (for a review of existing accessibility formulations see Geertman and Ritsema Van Eck (1995); Geurs and van Wee (2004); Martín, Reggiani, and Martin (2007); Páez, Scott, and Morency (2012); and Reggiani (2012). Accessibility measurement is a key issue in current research into transportation analysis (Farrington, 2007; Geurs \& van Wee, 2004); as recently stated: 'as long as the friction of distance continues to exist, accessibility will remain a relevant component of transportation studies' (Páez et al., 2012).

Accessibility indicators are increasingly being used to measure issues related to the implications of transport infrastructure investments for territorial cohesion (GonzálezGonzález \& Nogués, 2016; Jacobs-Crisioni et al., 2016; L’Hostis et al., 2002; Ortega, López, et al., 2014). In the case of HSR, the building of a new corridor alters the spatial accessibility pattern, and some regions benefit (relatively) more than others in terms of accessibility (Martínez Sanchez-Mateos \& Givoni, 2012; Ureña et al., 2009; Vickerman, 2015b). The degree of equality in accessibility levels can therefore be measured by the spatial distribution of accessibility levels across a given territory (Bröcker et al., 2010; López et al., 2008; Ortega et al., 2012; Ortega, López, et al., 2014; Talen \& Anselin, 1998). HSR must contribute to a more balanced distribution of accessibility if it is to correct territorial imbalances.

Most studies on accessibility and cohesion/equity issues so far have been carried out at micro/local levels, where 'desired' destinations usually refer to urban facilities such as 
healthcare services, playgrounds, emergency services facilities (ESFs) or urban parks (Coffee et al., 2012; Hare \& Barcus, 2007; Langford \& Higgs, 2006; McGrail \& Humphreys, 2009; Novak \& Sullivan, 2014; Sanders, Aguilar, \& Bacon, 2013; Talen \& Anselin, 1998; Wang, 2012; Yang, Goerge, \& Mullner, 2006); or the detection of 'food deserts', i.e. locations with a lack of access to sources of healthy food (Farber, Morang, \& Widener, 2014; Hallett \& McDermott, 2011; Sparks, Bania, \& Leete, 2011). Additional evidence is provided by Yang et al. (2006) who examined the equitability of dialysis service centres in Chicago. Other examples include the work of McGrail and Humphreys (2009), in a study measuring primary care service accessibility across rural areas of Victoria, Australia; the research by Luo and Qi (2009), calculating spatial access to primary care physicians in Illinois, USA; or the recently developed spatial access ratio (SPAR) concept (Wan, Zhan, Zou, \& Chow, 2012), applied to assess access to colorectal cancer services in Texas, USA. Research on this topic is intended to ascertain the degree of inequality in the access to key urban facilities in a given territory so as to detect isolated areas and consequently suggest policy initiatives to reduce these disparities.

A different approach is needed when studying the accessibility provided by HSR networks. These studies are usually carried out at strategic planning levels, such as national or international macro levels. This broader scope means that accessibility indicators must be calculated based on restrictions in data availability (basically detailed travel and mobility data), and the affordability of the corresponding computation efforts. On this coarser scale, travel times are calculated using long-distance transport networks, and major urban agglomerations are usually selected as 'desired' destinations (Bröcker et al., 2010; López et al., 2008; Martínez Sanchez-Mateos \& Givoni, 2012; Monzón et al., 2013; Zhang, Nian, \& Lyu, 2016). These studies focus on accessibility provided by the HSR network, i.e. using the HSR network. Other research works focus on accessibility to the HSR network, i.e. to the nearest HSR station, which refers to the role of access/egress trips (or 'first/last mile trips') in the overall HSR trip (Monzón, Ortega, \& López, 2016). These studies highlight the importance of the quality of access to the HSR station, as in HSR 'most of the travel time (and effort) is spent on getting to and from the HSR station, and this constitutes the bulk of the journey travel time' (Givoni \& Banister, 2012, p. 306).

The effects of HSR developments extend even further from HSR stations and their hinterlands (Garmendia et al., 2012; Gutiérrez, Condeço-Melhorado, \& Martín, 2010; Martín et al., 2007), spreading beyond HSR corridors, i.e. generating spillover effects (Gutiérrez et al., 2010; Ortega et al., 2012). Accessibility indicators are efficient tools to evaluate these effects, which are of crucial importance in research into territorial cohesion. In particular, recent studies highlight the effects of new HSR corridors on intermediate cities that are near HSR stations but do not have one themselves, as they could be relatively negatively affected after the construction of a new HSR line (Martínez Sanchez-Mateos \& Givoni, 2012; Monzón et al., 2013; Naranjo Gómez, 2016; Ureña et al., 2009; Vickerman, 2015b).

In general, evidence on the cohesion effects of HSR so far has shown that the risk of HSR inducing spatial inequalities should be considered in the early planning stages (GonzálezGonzález \& Nogués, 2016; López et al., 2008; Monzón et al., 2013; Ortega et al., 2012; Ortega, López, et al., 2014) to enhance the connectivity of HSR networks and reduce the risk of polarization. This requires transport planners to efficiently interconnect HSR stations with secondary transport networks and local public transport in order to reduce 
access/egress travel times (Givoni \& Banister, 2012; Monzón et al., 2013, 2016; Mota, López, \& Martínez-Rodrigo, 2017). Given these planning challenges, strategic spatial planning methodologies are valuable tools for addressing the complex issue of territorial cohesion: this is the case of our accessibility-based approach, which is described below.

\section{Methodology for determining 'accessibility-based' territorial cohesion impacts of HSR}

The methodology is based on the assessment of the distribution of the accessibility changes and territorial cohesion impacts caused by the HSR network extension in Spain during a 25 year-period: 1990-2015. The methodology determines the differences between two types of indicators -accessibility and territorial cohesion-throughout the implementation of different HSR projects. The effect is measured by calculating the values of the indicators for different horizon years: 1990 (before starting HSR), 1995, 2000, 2005, 2012 and 2015. It therefore combines a cross-country analysis for each year with a longitudinal analysis to measure the evolution over the period. Both transport networks and population are updated for each horizon year.

The differences between each two consecutive horizon years reveal the changes in accessibility due to the HSR lines implemented in that particular period. The territorial cohesion indicator is based on the spatial distribution of accessibility levels in the territory. The whole procedure is supported by a Geographical Information System (GIS), which includes all land transport networks and population distribution values throughout the 1990-2015 period. The accessibility indicator considers the travel time for three stages: road access to the station, rail service, and egress by road to final destination.

\subsection{Method for calculating potential accessibility changes}

The first step in the accessibility calculations was the implementation of road and rail transport network datasets in GIS. The changes are assessed by comparing the accessibility levels modelled for each horizon year. The GIS databases needed for each horizon year are: (i) road network with attributes that contain typology and speed; (ii) rail network with attributes of typology, speed and penalties; and (iii) the location of origins and destinations with information on their population. The access and egress road links are mainly local/ regional roads with no major changes in level of service throughout the period of analysis.

The Potential Accessibility Indicator (López et al., 2008; MartÍn, Gutiérrez, \& Román, 2004) described in equation (1) was selected from among the wide spectrum of existing formulations to measure accessibility (see e.g. Reggiani, 1998) because it offers an adequate balance of complexity and interpretability, and has been used successfully to measure HSR effects in several research works (Gutiérrez, Condeço-Melhorado, López, \& Monzón, 2011; López et al., 2008; Monzón et al., 2013; Ortega et al., 2012)

$$
P A_{i}=\sum_{j} \frac{P_{j}}{I_{i j}}
$$

$P A_{i}$ is the potential accessibility for each origin $i$ to all destinations $j . P_{j}$ is a variable referring to the activity level of each destination -population- and $\left(I_{i j}\right)$ is the generalized travel 
time using the rail network. The formulation for the travel time is as follows (Equation (2)):

$$
I_{i j}=T T_{R}\left(i, E_{i}\right)+T T_{F}\left(E_{i}, E_{j}\right)+T T_{R}\left(E_{j}, j\right)+\theta_{F}
$$

Equation (2) considers first the travel time by road from the origin to the nearest station $\left(T T_{R}\left(i, E_{i}\right)\right)$, the travel time using the railway network to the station nearest the destination $\left(T T_{F}(i, j)\right)$ and the travel time by road from this station to the destination itself $\left(T_{R}\left(E_{j}, j\right)\right)$. It also considers a set of penalties $\left(\theta_{F}\right)$ : frequency of service, railway line change, road to railway mode change and gauge change, as used in López, Monzón, Ortega, and Mancebo (2009). The frequency penalty is calculated according to the empirical model defined by Megía (2002), which depends on the origin and destination population, distance and travel time between each O-D pair. In our case, the model was calibrated using real frequencies from Madrid and Barcelona to the rest of Spanish capital cities. The frequency penalty corresponds to $15 \mathrm{~min}$ for each hour of railway travel time. Road-rail transfer is assumed to be $30 \mathrm{~min}$ on average, including waiting time. The time spent on gauge changers is fixed at $20 \mathrm{~min}$. All the calculations were implemented in a GIS programmed in Arc Macro Language for ArcInfo workstation. The detailed description of this process can be seen in Ortega, Mancebo, and Otero (2011).

The aggregated value of Potential Accessibility in each horizon year $(H x)$ is therefore calculated as follows:

$$
P A^{H x}=\frac{P A_{i}^{H x} \cdot P_{i}^{H x}}{\sum_{i} P_{i}^{H x}}
$$

$P A^{H x}$ is the aggregated accessibility value for the $\mathrm{Hx}$ horizon year; $\mathrm{P} A_{i}^{H x}$ is the accessibility value in the origin $I$, and $P_{i}^{H x}$ is the population in the origin $i$, both for the year $H_{x}$.

The change in the accessibility values between two horizon years allows the effects of the HSR projects implemented in the period between them to be assessed. The difference in accessibility is calculated as a percentage of the potential accessibility change. The changes between two consecutive horizon years will be as follows (equation (4)):

$$
\mathrm{PAC}^{H x-H x+1}=\frac{P A^{H x}-P A^{H x+1}}{P A^{H x}} * 100
$$

$P A C^{H x-H x+1}$ is the change in the values of the potential accessibility indicator between two horizon years $H_{x}$ and $H_{x+1}$.

A positive $P A C$ value indicates an increase in accessibility in the year $H_{x+1}$ compared to year $H_{x}$ in the whole territory. The higher PAC values therefore mean greater accessibility improvements for the whole population in a specific territory.

\subsection{Method for calculating the 'accessibility-based' territorial cohesion index}

Once the differences in accessibility are determined in the different periods of building the HSR network, it is advisable to calculate whether these accessibility gains are equally distributed in the territory. The dispersion of accessibility values is a measure of 'accessibilitybased' territorial cohesion which must be analyzed together with the overall increase in accessibility. It could be the case that increases in accessibility when considering the 
country as a whole could be caused by very high increases in some locations and much lower in others. The final result could exacerbate the differences between regions and lead to losses in territorial cohesion.

This effect is measured by calculating the potential accessibility dispersion index (PAD) (Ortega et al., 2012), based on the coefficient of variation, as applied in other similar studies (López et al., 2008; López \& Monzón, 2010). Equation (5) shows its formulation.

$$
P A D^{H x}=\frac{\sigma^{H x}}{\frac{\sum P A_{i}^{H x} \cdot P_{i}^{H x}}{\sum P_{i}^{H x}}}
$$

Where $P A D^{H x}$ is the coefficient of variation in the horizon year $H_{x}$, and $\sigma^{H x}$ is the standard deviation of $P A_{i}^{H x}$ values, weighted by the population $P_{i}^{H x}$. High $P A D$ values mean more polarized accessibility distributions, and less territorial cohesion.

Finally, the change in the 'accessibility-based' territorial cohesion (in what follows, territorial cohesion) between horizon years is measured using the 'accessibility-based' territorial cohesion index (in what follows, TC) as defined by Ortega et al. (2012), which is mathematically expressed in equation (6):

$$
T C^{H_{x}-H_{x+1}}=\frac{P A D^{H_{X}}-P A D^{H_{X+1}}}{P A D^{H_{x}}} \times 100
$$

Where TC is the change in territorial cohesion between two horizon years: $H_{x}$ and $H_{x+1}$. A positive $T C$ value means an increase in territorial cohesion between the two horizon years.

In order to complete this analysis, the normalized value of the PA for each horizon year is calculated for each city. A value of 1 is assigned as the average value. If the PA value is below average, it will have a value of less than 1; and if the accessibility value is above average, it will be greater than 1 . Once the values are mapped, they reveal which cities have higher accessibility values than others, and whether the improvements are uniformly distributed (approximate average values) between two years.

\section{Accessibility and territorial cohesion analysis of the 1990-2015 period in Spain}

The research evaluates territorial cohesion impacts due to HSR investments in Spain over 25 years. 1990 is the reference horizon year, before starting the HSR plan. The construction timelines were as follows:

Figure 1 shows the development of the network with these HSR projects.

To calculate the accessibility values, the indicators were calculated for the horizon years. The infrastructure investments considered had a commercial speed of 180$220 \mathrm{~km} / \mathrm{h}$ and were built in Spain in this 25-year period. Accessibility values have been calculated for all the cities in the study area, and the analysis of equity effects focused on the whole of mainland Spain and a selection of major cities. The study area comprises the Spanish mainland at the municipality level, which includes a total of 7953 municipalities. The 278 Portuguese concelhos and 19 French districts are also considered as potential destinations. 


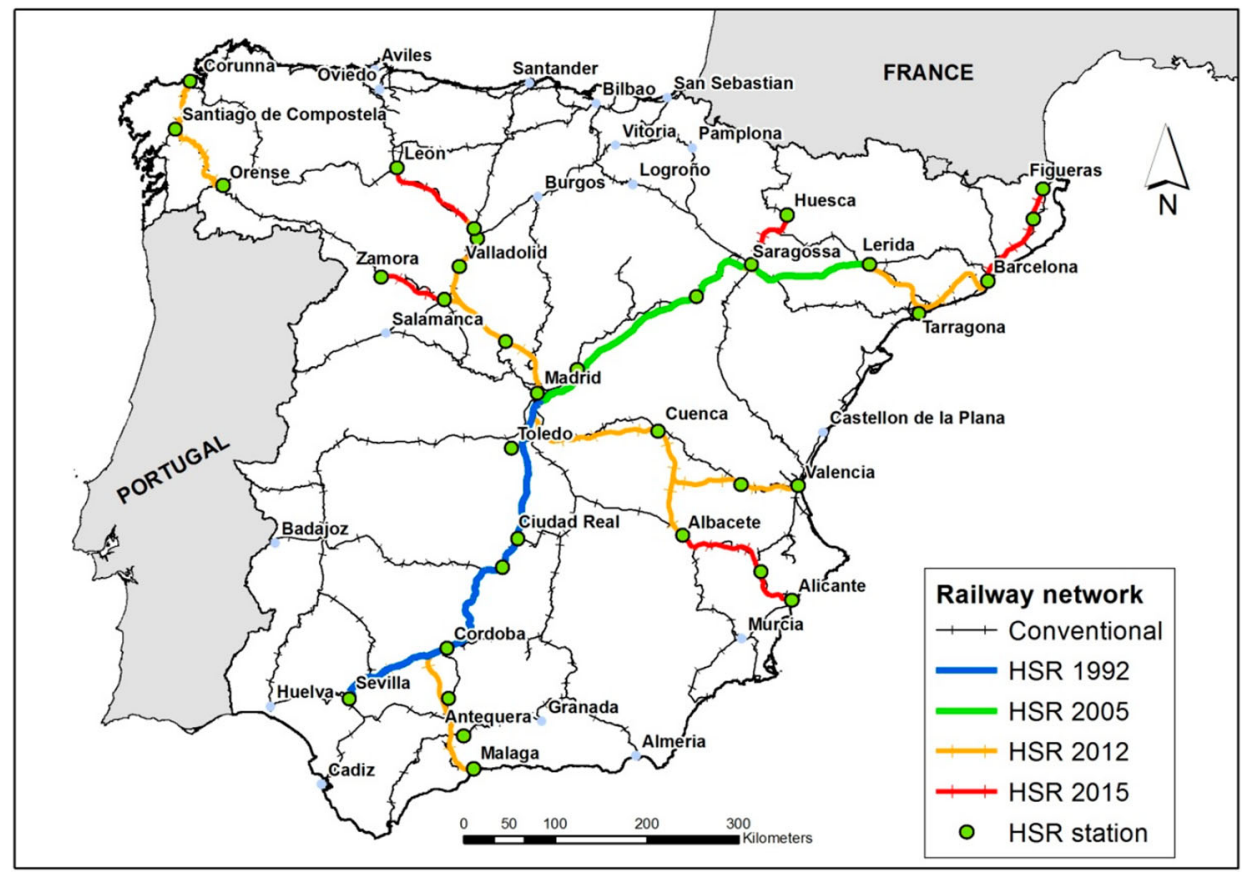

Figure 1. Situation of the Spain HSR network from 1992 to 2015.

\subsection{Accessibility results}

Figure 1 shows the HSR corridors in each horizon year, with the location of the HSR stations. The socioeconomic data (population) in each situation correspond to the respective year. Accessibility values were calculated by applying a vectorial GIS, in which the road and railway networks were modelled independently. The road network is necessary as a complement to the rail network to obtain the part of the trip that includes the access to the station from the origin and the egress from the station at the destination. Each of these GIS databases contains the length and estimated speed according to the type of infrastructure.

The railway network also includes information on track gauge (Iberian/UIC), station location and service frequency in order to calculate travel times, as described in López et al. (2009) and López and Monzón (2010). The origins and destinations (Spanish, Portuguese and French) in the study area are characterized in terms of population data. The accessibility indicators were calculated by connecting each city to all the other cities in the country. Each GIS database differentiates the information dynamically according to the six horizon years for the transport networks, service times and population.

Once the GIS databases have been created, the next step involves calculating the travel time between each origin-destination pair. The results and the destination population data are then entered in Equation (1) to obtain the potential accessibility value $\left(\mathrm{PA}_{\mathrm{i}}\right)$ for each of the 7953 Spanish municipalities. Accessibility was calculated using a GIS network accessibility toolbox: TITIM-GIStool (Ortega, Pastor, \& Mancebo, 2014). It also calculates the 
aggregated accessibility value for each year. The accessibility maps for the whole territory are built using a GIS interpolation technique from the cities' values.

Table 1 shows the accessibility results (PA) in each time horizon (expressed in thousands) and the percentage changes in accessibility (PAC) in different time periods, in provincial capitals with more than 150,000 inhabitants. These values are graphically represented in Figures 2 and 3. Figure 2 shows the accessibility values (PA) in each time horizon from 1990 to 2015, and Figure 3 shows the percentage of accessibility changes (PAC) between the two periods 1990-2005 (upper left), 2005-2015 (upper right), and the total change from 1990 to 2015 (lower).

As can be seen in Figure 2, in 1990, before the first HSR link was built, the areas with higher levels of accessibility were located in the Madrid-East and Mediterranean corridors. These were areas with good-quality conventional rail lines, with cities such as Madrid, Barcelona and Valencia showing accessibility levels significantly above the national average (see 1990 values in Table 2). The areas with the lowest accessibility levels were located in the north, where the cities had a very poor level of rail service and slow commercial speeds due to the presence of mountains and very narrow winding alignments. Their rail connexions to the main economic centres in the country were therefore extremely deficient. Regions near the Portuguese border -most of them rural- also suffered from low accessibility values.

The construction of the Madrid-Seville HSR link in 1992 improved accessibility levels in the southwest, and its effects expanded to other areas of the country, as shown by the percentage changes in the $90-95$ period, with a $30.5 \%$ improvement in Seville. This effect was further enhanced in 2005 with the construction of the new Madrid-Northeast corridor, when Saragossa increased its accessibility value by $33.5 \%$ in the 2000-2005 period. Accessibility levels rose significantly in the 2005-2012 period with the completion of the Madrid-NW and Madrid-East corridors. A number of cities in the corridors are highlighted, as in the case of Corunna $(34.3 \%)$, Valencia (29.9\%), and Valladolid (65.1\%); the effect spread to cities where new links were built, such as the Cordoba-Malaga link, which substantially improved accessibility in Malaga (48.5\%). In general, from 2005 to 2015 the improvements were concentrated in the NW and East. The mean national values of improvement for these periods were $21.2 \%$ and $22.6 \%$ respectively.

The total accessibility changes from 1990 to 2015 are very high, with an average improvement of $48.6 \%$ nationwide. The changes extend to the whole country, but the less benefited areas are the north, NW and west of Spain. In general, the greatest improvements in accessibility are concentrated in the areas around HSR stations, except in very large urban agglomerations such as Madrid. This is because HSR lines allow other major cities to be reached within a shorter travel time. Higher accessibility changes are common in the vicinity of these stations, such as Cuenca, Ciudad Real, Valladolid or Cordoba.

The cities in the analysis saw significant accessibility improvements from 1990 to 2015 (see the last column in Table 2) of at least 25\%, except in the case of Bilbao, which does not yet have a HSR connection. The cities with a new HSR station achieved high improvements, but the value depends on their initial accessibility values. Madrid and Barcelona show a lower improvement than others due to their favourable initial situation; while in cities with low accessibility levels before the construction of their HSR line such as 
Table 1. Accessibility values (in thousands) and their changes (\%) in different time periods.

\begin{tabular}{|c|c|c|c|c|c|c|c|c|c|c|c|c|c|c|}
\hline \multirow[b]{2}{*}{ ArealYear } & \multicolumn{6}{|c|}{ Accessibility values (PA) } & \multicolumn{8}{|c|}{ PA change (\%) (PAC) } \\
\hline & 1990 & 1995 & 2000 & 2005 & 2012 & 2015 & $90-95$ & $95-00$ & $00-05$ & $05-12$ & $12-15$ & $90-05$ & $05-15$ & $90-15$ \\
\hline National average & 128 & 136 & 144 & 155 & 184 & 190 & 6.1 & 6.3 & 7.5 & 18.5 & 3.4 & 21.2 & 22.6 & 48.6 \\
\hline Albacete & 132 & 138 & 148 & 153 & 175 & 212 & 4.5 & 7.7 & 3.3 & 13.9 & 21.5 & 16.3 & 38.3 & 60.8 \\
\hline Alicante & 127 & 132 & 144 & 148 & 172 & 193 & 4.1 & 9.1 & 2.8 & 15.6 & 12.5 & 16.8 & 30.0 & 51.9 \\
\hline Almeria & 84 & 87 & 92 & 96 & 117 & 118 & 2.9 & 6.7 & 4.3 & 20.9 & 0.9 & 14.5 & 21.9 & 39.6 \\
\hline Badajoz & 91 & 93 & 99 & 105 & 122 & 123 & 2.9 & 5.7 & 6.1 & 16.5 & 1.1 & 15.4 & 17.8 & 35.9 \\
\hline Barcelona & 210 & 215 & 224 & 242 & 263 & 263 & 2.5 & 4.2 & 8.2 & 8.6 & 0.1 & 15.5 & 8.6 & 25.5 \\
\hline Bilbao & 117 & 119 & 123 & 127 & 132 & 134 & 2.1 & 3.0 & 3.3 & 3.8 & 1.6 & 8.5 & 5.5 & 14.5 \\
\hline Burgos & 113 & 118 & 124 & 128 & 145 & 149 & 4.4 & 5.0 & 3.2 & 13.3 & 2.9 & 13.1 & 16.6 & 31.9 \\
\hline Cordoba & 118 & 164 & 173 & 186 & 225 & 231 & 39.3 & 5.5 & 7.5 & 21.2 & 2.4 & 57.9 & 24.1 & 95.9 \\
\hline Castellon de la Plana & 139 & 143 & 155 & 159 & 200 & 201 & 2.9 & 8.4 & 2.6 & 25.8 & 0.5 & 14.5 & 26.5 & 44.8 \\
\hline Granada & 98 & 102 & 105 & 110 & 140 & 142 & 3.6 & 3.7 & 4.6 & 27.0 & 1.5 & 12.3 & 28.9 & 44.7 \\
\hline Corunna & 82 & 84 & 85 & 88 & 118 & 128 & 1.7 & 1.7 & 3.2 & 34.3 & 8.7 & 6.8 & 45.9 & 55.8 \\
\hline Logrono & 104 & 108 & 114 & 129 & 146 & 149 & 3.7 & 5.8 & 12.9 & 13.5 & 1.8 & 23.9 & 15.6 & 43.2 \\
\hline Malaga & 105 & 117 & 123 & 130 & 193 & 198 & 11.6 & 5.0 & 6.0 & 48.5 & 2.1 & 24.2 & 51.6 & 88.3 \\
\hline Madrid & 282 & 296 & 314 & 337 & 384 & 393 & 5.0 & 5.9 & 7.2 & 14.0 & 2.5 & 19.2 & 16.8 & 39.3 \\
\hline Murcia & 122 & 127 & 139 & 144 & 166 & 178 & 4.3 & 9.9 & 3.1 & 15.3 & 7.3 & 18.2 & 23.8 & 46.4 \\
\hline Oviedo & 88 & 91 & 94 & 97 & 125 & 142 & 3.4 & 3.6 & 2.6 & 28.8 & 14.0 & 9.9 & 46.9 & 61.4 \\
\hline Pamplona & 96 & 105 & 104 & 115 & 142 & 145 & 9.5 & -1.1 & 11.0 & 23.4 & 1.8 & 20.2 & 25.6 & 51.0 \\
\hline San Sebastian & 100 & 97 & 108 & 115 & 120 & 122 & -3.1 & 11.0 & 6.8 & 4.5 & 1.2 & 14.9 & 5.8 & 21.6 \\
\hline Santander & 87 & 90 & 93 & 95 & 122 & 128 & 3.4 & 3.8 & 2.6 & 27.4 & 4.9 & 10.2 & 33.6 & 47.2 \\
\hline Seville & 123 & 161 & 168 & 179 & 211 & 215 & 30.5 & 4.3 & 6.4 & 18.1 & 1.9 & 44.9 & 20.4 & 74.5 \\
\hline Valencia & 172 & 176 & 190 & 194 & 253 & 255 & 2.4 & 7.6 & 2.4 & 29.9 & 0.9 & 12.8 & 31.0 & 47.8 \\
\hline Valladolid & 122 & 127 & 132 & 137 & 227 & 236 & 4.8 & 3.8 & 3.9 & 65.1 & 4.0 & 13.0 & 71.7 & 93.9 \\
\hline Vitoria & 110 & 114 & 120 & 125 & 145 & 148 & 3.2 & 5.4 & 4.0 & 16.3 & 2.0 & 13.2 & 18.6 & 34.3 \\
\hline Saragossa & 134 & 140 & 149 & 198 & 229 & 237 & 4.1 & 6.2 & 33.5 & 15.2 & 3.6 & 47.7 & 19.3 & 76.3 \\
\hline
\end{tabular}



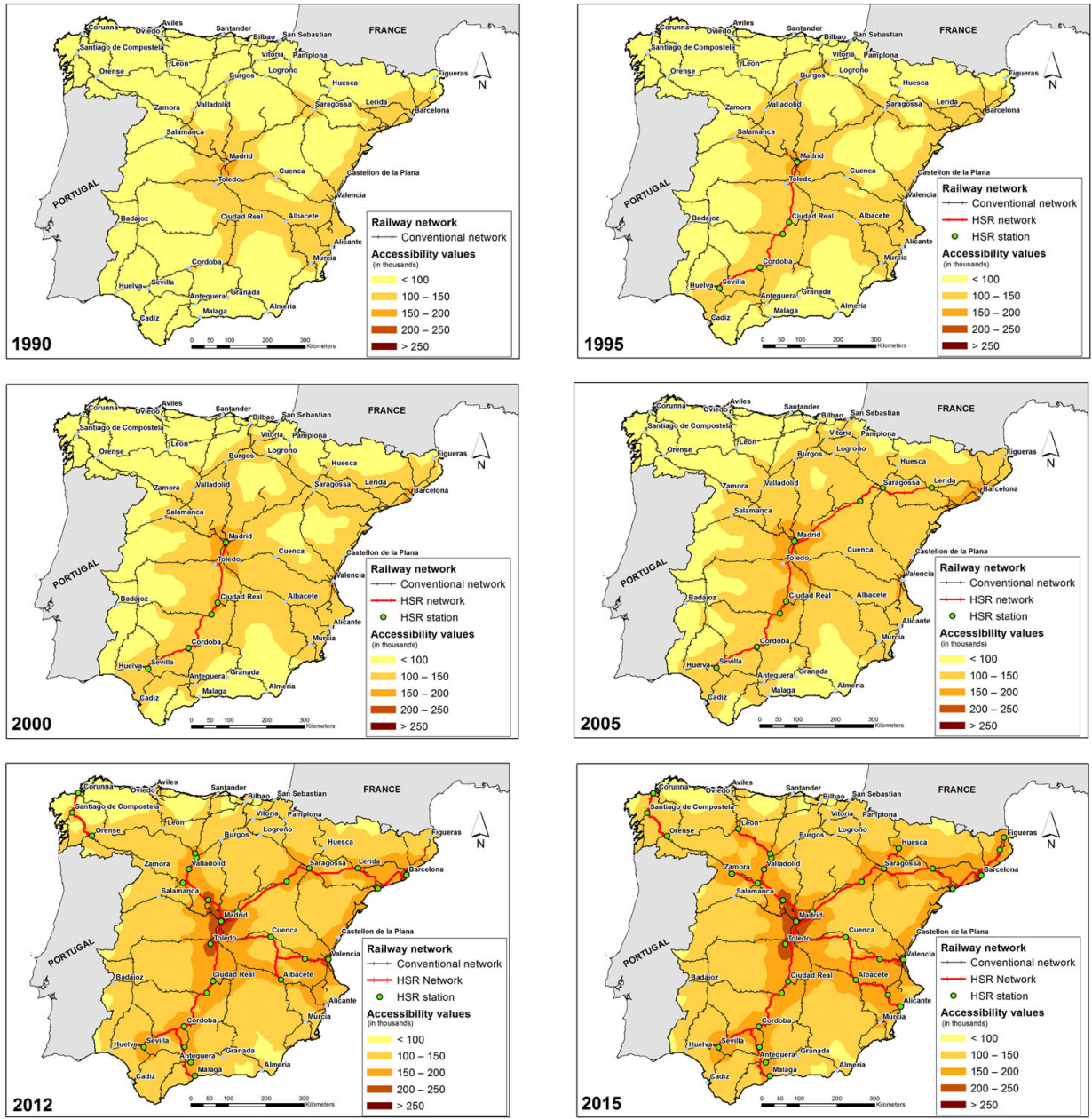

Figure 2. Accessibility maps in the years 1990, 1995, 2000, 2005, 2012 and 2015.

Seville, Malaga, Valladolid and Saragossa, the increase is very high (over 74\%). Figures 1-3 and the values in Table 2 show that the greatest changes in accessibility occur in the period when the new HSR extension connects the city with the HSR (see for example Albacete in 2012, Malaga in 2012 or Saragossa), although their accessibility levels had increased previously as they benefited from other HSR. This effect can also be seen in cities without HSR. In Badajoz, Santander and Vitoria the increase is $35.9 \%, 47.2 \%$ and $34.3 \%$ respectively. Although they have a conventional rail network, they can access HSR lines that allow them to reach remote destinations in very little time.

The new HSR extensions in the 2005-2015 period caused a greater improvement than those built in 1990-2005. This is due to the network effect and to the fact that the second period affected cities with lower accessibility values, improving the territorial balance of accessibility values. This will be confirmed in the following section, which addresses issues of territorial cohesion. 

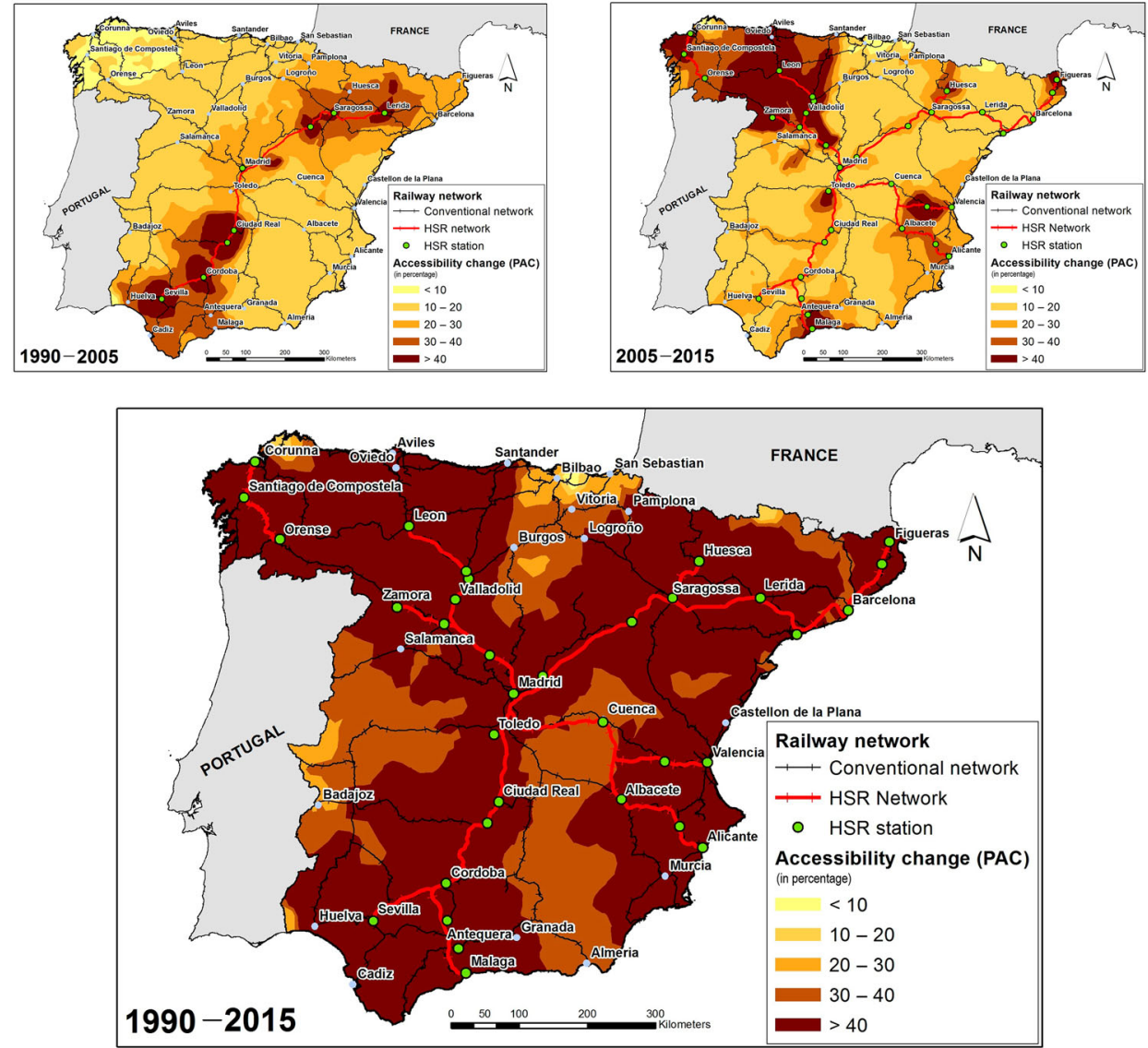

Figure 3. Accessibility changes between the years 1990-2005; 2005-2015 and 1990-2015.

Table 2. HSR project timelines and their length.

\begin{tabular}{llr}
\hline Year & \multicolumn{1}{c}{ HSR project } & Length $(\mathrm{km})$ \\
\hline 1992 & First HSR line Madrid-Seville (South) & 470 \\
2003 & Madrid-Saragossa-Lérida (NE) & 450 \\
2005 & Madrid-Toledo (S) & 75 \\
2006 & Lérida-Tarragona (NE) and Córdoba-Antequera (S) & 165 \\
2007 & Antequera-Málaga (SE) and Madrid-Valladolid (NW) & 240 \\
2008 & Tarragona-Barcelona (NE) & 100 \\
2010 & Madrid-Valencia/Albacete (E) & 400 \\
2011 & Orense-Santiago de Compostela-Corunna (NW) & 150 \\
2013 & Barcelona-Figueres (NE) and Albacete-Alicante (E) & 300 \\
2015 & Several sections connecting Huesca, Leon, Vigo, Zamora. & 340 \\
\hline
\end{tabular}

\section{2. 'Accessibility-based' territorial cohesion analysis}

Table 3 shows the Potential Accessibility Dispersion (PAD) values for the years considered, and the relative differences in 'accessibility-based' territorial cohesion (in \%) between years (TC), following Equations (5) and (6) respectively. It can be seen that the PAD value has decreased from 1990 to 2015, representing an increment in territorial 

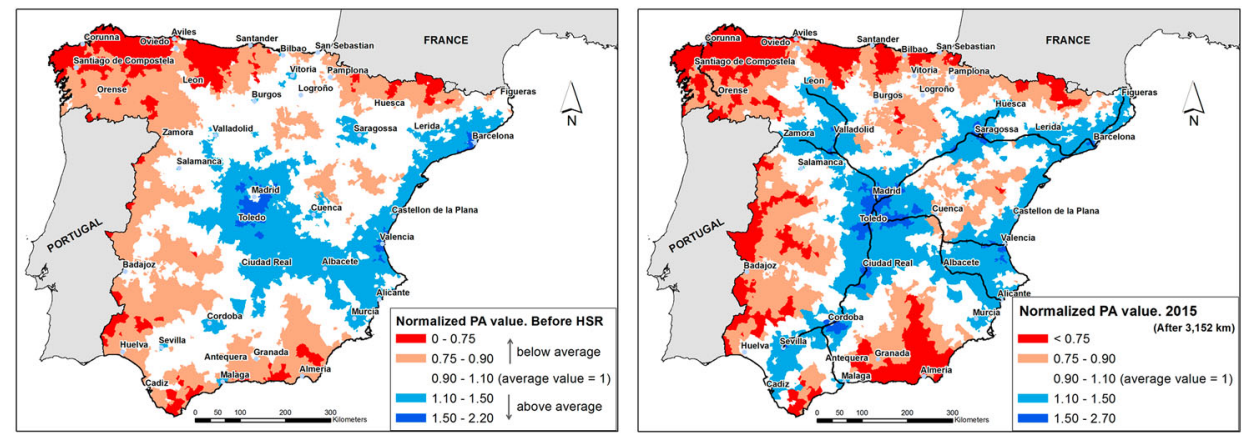

Figure 4. Normalized accessibility value before HSR (1990) and after 25 years (2015).

cohesion in Spain due to the reduction of differences in accessibility. Changes in territorial cohesion from 1990 to 2005 are moderate (4.5\%) and high from 2005 to 2015 (a 10.5\% improvement). This indicates that in this period the new HSR infrastructures have most benefited the cities with the lowest and highest accessibility levels.

For a better understanding of the territorial cohesion index, PA values have been normalized for the approximately 8100 Spanish municipalities (average national value $=1$ ) and graphically represented in Figure 4. The blue areas indicate that the values are $10 \%$ above average, the red areas that they are $90 \%$ below average, and the white areas have values in between this range.

The areas with highest accessibility values (blue areas, Figure 4) are mainly concentrated in the centre of the Iberian Peninsula and in the Mediterranean corridor. Some differences can be seen between 1990 and 2015. The area with above-average values is larger in 1990 than in 2015; this is the case of the southwest, centre-northwest and northeast. They may previously have had high accessibility levels and have benefited from the new HSR corridors. In contrast, some areas have increased their below-average values from 1990 to 2015. These areas had low accessibility levels in 1990 and obtained no HSR extensions in 2015. This is the case of certain areas in the west, south and northwest of Spain. The areas with average values are also larger in 1990 than in 2015. This would account for the reduction in the rate of TC from 1990 to 2015, although according to the values in Table 1, the TC has increased. This can be explained by the fact that the HSR stations are located in major cities, and the highest accessibility levels are concentrated in these large population centres, leading to above average accessibility values.

\section{Conclusions}

The construction of HSR links has been key in the development of European transport networks (Carvalho, Partidario, \& Sheate, 2017; Gutiérrez, González, \& Gómez, 1996; Vickerman, 2015a), although there is still some controversy regarding its wider impacts (Barrón et al., 2012; Garmendia et al., 2012; Vickerman, 2015a; Vickerman \& Ulied, 2009). New HSR links, when providing a more spatially balanced distribution of accessibility, can contribute to territorial cohesion goals, especially if integrated in a combined strategy derived from different sectoral policies. However, one research topic currently under debate concerns the risk that HSR may induce more polarized territorial 
Table 3. Comparison of potential accessibility dispersion and territorial cohesion results Potential Accessibility Dispersion Year/value

Territorial Cohesion (\%)

Period/value

\begin{tabular}{|c|c|c|c|c|c|c|c|c|c|c|c|c|c|}
\hline & \multicolumn{8}{|c|}{ 8. } \\
\hline 1990 & 1995 & 2000 & 2005 & 2012 & 2015 & 1990-1995 & $1995-2000$ & $2000-2005$ & $2005-2012$ & $2012-2015$ & $1990-2005$ & 2005-2015 & $1990-2015$ \\
\hline 0.46 & 0.44 & 0.43 & 0.44 & 0.40 & 0.39 & 3.6 & 1.7 & -0.8 & 7.8 & 2.9 & 4.5 & 10.5 & 14.5 \\
\hline
\end{tabular}


accessibility distributions, as it can be considered to have a negative impact on territorial cohesion (Garmendia et al., 2012; Martínez Sanchez-Mateos \& Givoni, 2012; Vickerman, $2015 b$ ). The research in this paper examines this trade-off between maximizing accessibility values vs. reducing disparities in the territorial distribution of accessibility.

Our findings show that the 25-year development plan of the HSR network in Spain has reduced connecting times in most cities and improved accessibility levels by an average of 49\% nationwide between 1990 and 2015. At the same time, better rail connections have reduced disparities among regions and achieved higher levels of territorial cohesion in the distribution of accessibility. It is also worth noting that the greatest benefits are not concentrated in the larger cities like Madrid and Barcelona, but in small to medium ones which had a relatively worse situation in 1990. At the beginning of the construction of the HSR network, efficiency goals were prioritized, hence the first links connected major population centres. As the network expanded, cohesion goals began to gain importance, and new corridors were built to connect peripheral areas in northern and northwestern areas. This has led to an overall improvement in territorial imbalances in accessibility, and contributes to achieving territorial cohesion goals. This development has been accompanied by evidence of a mode substitution effect: in the 1998-2016 period, long-distance rail passengers increased from $15,641,000$ to $31,792,000$. In the same period, air traffic declined on major routes competing with HSR services, with relevant examples being: Madrid-Seville (25\% drop in air traffic, 63\% rise in rail traffic), Madrid-Barcelona (34\% and 874\%) and Madrid-Valencia (42\% and 470\%) (Observatorio del Ferrocarril en España, 2017).

Following the ideas of Geurs and van Wee (2004), we should look not only at the transport services themselves but also at their land-use impacts. In this case, location and access to stations are key elements for capturing all the potential benefits of HSR developments (Monzón et al., 2013). However, in order to contribute to cohesion goals, strategic planning must include not only improvements in the HSR network, but also take account of first and last mile trips (Castillo-Manzano, Pozo-Barajas, \& Trapero, 2015; Givoni \& Banister, 2012; Monzón et al., 2016). This implies the challenge of integrating agents and stakeholders from different administrative levels and local public transport authorities, and also requires good connections with secondary rail and road networks (González-González \& Nogués, 2016; Zhang et al., 2016). It is therefore important not only to have a HSR station but also good accessibility by road to the station location (Monzón et al., 2013; Ureña et al., 2009; Vickerman, 2015b).

Another key result is the spillover effect resulting from HSR investments (Gutiérrez et al., 2010), which also has cohesion implications. Cities without HS services -e.g. Santander and Aviles in the north or Cadiz in the south- show almost the same improvements as others with high-speed rail services and stations. The reason is that these cities now have the possibility of partial high-speed connections with major economic centres, and the links connecting to the HSR network are of relatively good quality. This has been a good policy facilitated by the technical innovation of transfer devices from the HS to the Spanish track with a different gauge. In other words, investments in secondary rail networks can significantly improve the effects of new HSR links on territorial cohesion. Finally, there are some areas where changes in accessibility levels are lower, as shown in Figure 3. These are Extremadura (west connecting to Portugal), the Basque Country (north connecting to France) and Granada-Almeria (southeast). These three areas of 
lower accessibility are expected to improve in the coming years due to ongoing building projects for new HSR extensions. When these projects in the HSR network are completed, territorial cohesion values are expected to improve nationwide.

The assessment of territorial cohesion impacts of new HSR links is an ambitious, complex, and multidimensional task (Bröcker et al., 2010; Jacobs-Crisioni et al., 2016; Peters, 2003). In this paper we have approached the territorial cohesion issue from an accessibility perspective: evaluating the extent that HSR has reduced (or increased) spatial disparities in accessibility values. We acknowledge that, in order to derive conclusions on territorial cohesion impacts, our findings would necessarily require to be integrated in a wider assessment framework, including a full range of costs and benefits (Button, 2012; de Rus, 2011; Nash, 2015; Preston, 2009; Vickerman, 2015a). It would also be desirable to consistently and effectively prioritize the next HSR links to be built, in order to transform the current 'ineffective patchwork' (European Union, 2018) into a real European HSR network. It would be also of interest to investigate the impact of secondary stations which improve territorial accessibility to small-medium size locations, but result in an increase of construction and operating costs. Those costs depend also on the typology of the station, if the line just pass through or require additional $\mathrm{km}$ of rail infrastructure.

Finally, additional difficulties arise from the high degree of uncertainty involved in this long term evaluations, regarding variables such as economic growth or demand forecasts. Further research is still needed for the complex task of developing these reliable appraisal methodologies, in which we believe spatial analysis based on accessibility indicators may result of significant help for transport planners.

\section{Disclosure statement}

No potential conflict of interest was reported by the authors.

\section{ORCID}

Andres Monzon (D) http://orcid.org/0000-0001-7265-2663

\section{References}

Barrón, I., Campos, J., Gagnepain, P., Nash, C., Vickerman, R., \& Ulied, A. (2012). Economic analysis of high speed rail in Europe (G. de Rus, Ed.) Economic analysis of high speed rail in Europe. Bilbao: Fundación BBVA.

Beria, P., Grimaldi, R., Albalate, D., \& Bel, G. (2018). Delusions of success: Costs and demand of high-speed rail in Italy and Spain. Transport Policy, 68, 63-79. doi:10.1016/j.tranpol.2018.03.011

Bröcker, J., Korzhenevych, A., \& Schürmann, C. (2010). Assessing spatial equity and efficiency impacts of transport infrastructure projects. Transportation Research Part B: Methodological, 44(7), 795-811. doi:10.1016/j.trb.2009.12.008

Button, K. (2012). Is there any economic justification for high-speed railways in the United States? Journal of Transport Geography, 22, 300-302. doi:10.1016/j.jtrangeo.2012.01.025

Campos, J., \& de Rus, G. (2009). Some stylized facts about high-speed rail: A review of HSR experiences around the world. Transport Policy, 16(1), 19-28. doi:10.1016/J.TRANPOL.2009.02.008

Carvalho, S., Partidario, M., \& Sheate, W. (2017). High speed rail comparative strategic assessments in EU member states. Environmental Impact Assessment Review, 66, 1-13. doi:10.1016/j.eiar. 2017.05.006 
Castillo-Manzano, J. I., Pozo-Barajas, R., \& Trapero, J. R. (2015). Measuring the substitution effects between high speed rail and air transport in Spain. Journal of Transport Geography, 43, 59-65. doi:10.1016/j.jtrangeo.2015.01.008

CEC. (1999). ESDP European spatial development perspective. Towards Balanced and Sustainable Development of the Territory of the European Union. Office for Official Publications of the European Communities, Luxembourg.

CEC. (2008). Green paper on territorial cohesion: Turning territorial diversity into strength. Communication from the Commission to the Council, the European Parliament, the Committee of the Regions and the European Economic and Social Committee. European Commission, Brussels, Belgium.

Clifton, J., Díaz-Fuentes, D., \& Fernández-Gutiérrez, M. (2016). Public infrastructure services in the European Union: Challenges for territorial cohesion. Regional Studies, 50(2), 358-373. doi:10. 1080/00343404.2015.1044958

Coffee, N., Turner, D., Clark, R. A., Eckert, K., Coombe, D., Hugo, G., ... Tonkin, A. A. (2012). Measuring national accessibility to cardiac services using geographic information systems. Applied Geography, 34, 445-455. doi:10.1016/j.apgeog.2012.01.007

Crozet, Y. (2014). Extension of the high speed rail network in France: Facing the curse that affects PPPs in the rail sector. Research in Transportation Economics, 48, 401-409. doi:10.1016/J. RETREC.2014.09.065

Davoudi, S. (2005). Understanding territorial cohesion. Planning Practice \& Research, 20(4), 433441. doi:10.1080/02697450600767926

de Rus, G. (2011). The BCA of HSR: Should the government invest in high speed rail infrastructure? Journal of Benefit-Cost Analysis, 2(1), 1-28. doi:10.2202/2152-2812.1058

EC. (2011). EC/European Commission. White Paper. Roadmap to a Single European Transport Area - Towards a competitive and resource efficient transport system. COM(2011) 144 Final, Brussels, European Commission. Retrieved from http://ec.europa.eu/transport/index_en.htm

European Union. (2018). A European high-speed rail network: Not a reality but an ineffective patchwork.

Faludi, A. (2004). The European spatial development perspective and North-West Europe: Application and the future. European Planning Studies, 12(3), 391-408. doi:10.1080/ 0965431042000195010

Faludi, A. (2006). From European spatial development to territorial cohesion policy. Regional Studies, 40(6), 667-678. doi:10.1080/00343400600868937

Farber, S., Morang, M. Z., \& Widener, M. J. (2014). Temporal variability in transit-based accessibility to supermarkets. Applied Geography, 53, 149-159. doi:10.1016/j.apgeog.2014.06.012

Farrington, J. H. (2007). The new narrative of accessibility: Its potential contribution to discourses in (transport) geography. Journal of Transport Geography, 15(5), 319-330. doi:10.1016/j. jtrangeo.2006.11.007

Flyvbjerg, B., Bruzelius, N., \& Rothengatter, W. (2003). Megaprojects and risk: An anatomy of ambition. Cambridge: Cambridge University Press.

Garmendia, M., Ribalaygua, C., \& Ureña, J. (2012). High speed rail: Implication for cities. Cities, 29, S26-S31. doi:10.1016/j.cities.2012.06.005

Geertman, S. C. M., \& Ritsema Van Eck, J. R. (1995). GIS and models of accessibility potential: An application in planning. International Journal of Geographical Information Systems. doi:10.1080/ 02693799508902025

Geurs, K. T., \& van Wee, B. (2004). Accessibility evaluation of land-use and transport strategies: Review and research directions. Journal of Transport Geography, 12, 127-140. doi:10.1016/j. jtrangeo.2003.10.005

Givoni, M. (2006). Development and impact of the modern high-speed train: A review. Transport Reviews, 26(5), 593-611. doi:10.1080/01441640600589319

Givoni, M., \& Banister, D. (2012). Speed: The less important element of the high-speed train. Journal of Transport Geography, 22, 306-307. doi:10.1016/j.jtrangeo.2012.01.024 
González-González, E., \& Nogués, S. (2016). Regional polycentricity: An indicator framework for assessing cohesion impacts of railway infrastructures. European Planning Studies, 24(5), 950973. doi:10.1080/09654313.2016.1142506

Gutiérrez, J., Condeço-Melhorado, A., \& Martín, J. (2010). Using accessibility indicators and GIS to assess spatial spillovers of transport infrastructure investment. Journal of Transport Geography, 18(1), 141-152. Retrieved from http://www.sciencedirect.com/science/article/pii/ S096669230800152X

Gutiérrez, J., Condeço-Melhorado, A., López, E., \& Monzón, A. (2011). Evaluating the European added value of TEN-T projects: a methodological proposal based on spatial spillovers, accessibility and GIS. Journal of Transport Geography, 19(4), 840-850. doi:10.1016/j.jtrangeo.2010.10.011

Gutiérrez, J., González, R., \& Gómez, G. (1996). The European high-speed train network: Predicted effects on accessibility patterns. Journal of Transport Geography, 4, 227-238. doi:10.1016/S09666923(96)00033-6

Hallett, L. F., \& McDermott, D. (2011). Quantifying the extent and cost of food deserts in Lawrence, Kansas, USA. Applied Geography, 31(4), 1210-1215. doi:10.1016/j.apgeog.2010.09.006

Hare, T. S., \& Barcus, H. R. (2007). Geographical accessibility and Kentucky's heart-related hospital services. Applied Geography, 27(3-4), 181-205. doi:10.1016/j.apgeog.2007.07.004

Jacobs-Crisioni, C., Batista e Silva, F., Lavalle, C., Baranzelli, C., Barbosa, A., \& Perpiña Castillo, C. (2016). Accessibility and territorial cohesion in a case of transport infrastructure improvements with changing population distributions. European Transport Research Review, 8(1), 9. doi:10. 1007/s12544-016-0197-5

Langford, M., \& Higgs, G. (2006). Measuring potential access to primary healthcare services: The influence of alternative spatial representations of population. The Professional Geographer, 58(3), 294-306. doi:10.1111/j.1467-9272.2006.00569.x

L'Hostis, A., Mathis, P., Reynaud, C., Spiekermann, K., Ulied, A., \& Wegener, M. (2002). Research project ESPON 1.2. 1. On transport servives and networks. Territorial trends and basic supply of infrastructure. ESPON Coordination Unit. Luxembourg.

López, E., Gutiérrez, J., \& Gómez, G. (2008). Measuring regional cohesion effects of large-scale transport infrastructure investments: An accessibility approach. European Planning Studies, 16 (2), 277-301. doi:10.1080/09654310701814629

López, E., \& Monzón, A. (2010). Integration of sustainability issues in strategic transportation planning: a multi-criteria model for the assessment of transport infrastructure plans. Computer Aided Civil and Infrastructure Engineering, 25(6), 440-451. doi:10.1111/j.1467-8667.2010.00652.x

López, E., Monzón, A., Ortega, E., \& Mancebo, S. (2009). Assessment of cross-border spillover effects of national transport infrastructure plans: an accessibility approach. Transport Reviews, 29(4), 515-536. doi:10.1080/01441640802627974

Luo, W., \& Qi, Y. (2009). An enhanced two-step floating catchment area (E2SFCA) method for measuring spatial accessibility to primary care physicians. Health and Place, 15, 1100-1107. doi:10.1016/j.healthplace.2009.06.002

Malecki, E. J. (2014). Connecting the fragments: Looking at the connected city in 2050. Applied Geography, 49, 12-17. doi:10.1016/j.apgeog.2013.09.004

Malý, J. (2016). Questioning territorial cohesion: (Un)equal access to services of general interest. Papers in Regional Science. doi:10.1111/pirs.12250

MartÍn, J., Gutiérrez, J., \& Román, C. (2004). Data envelopment analysis (DEA) index to measure the accessibility impacts of new infrastructure investments: The case of the high-speed train corridor Madrid- Barcelona-French Border. Regional Studies, 38(6), 697-712. doi: 10.1080/ 003434042000240987

Martín, J. C., Reggiani, A., \& Martin, J. (2007). Recent methodological developments to measure spatial interaction: Synthetic accessibility indices applied to high-speed train investments. Transport Reviews, 27, 551-571. doi:10.1080/01441640701322610

Martínez Sanchez-Mateos, H. S., \& Givoni, M. (2012). The accessibility impact of a new high-speed rail line in the UK - a preliminary analysis of winners and losers. Journal of Transport Geography, 25, 105-114. doi:10.1016/j.jtrangeo.2011.09.004 
McGrail, M. R., \& Humphreys, J. S. (2009). Measuring spatial accessibility to primary care in rural areas: Improving the effectiveness of the two-step floating catchment area method. Applied Geography, 29(4), 533-541. doi:10.1016/j.apgeog.2008.12.003

Medeiros, E. (2016). Territorial cohesion: An EU concept. European Journal of Spatial Development, 60, 1-30.

Megía, M. J. (2002). Oferta de transporte de viajeros por ferrocarril entre ciudades importantes de la Unión Europea. Estudios de Construcción y Transportes, 95, 71-92.

Monzón, A., Ortega, E., \& López, E. (2013). Efficiency and spatial equity impacts of high-speed rail extensions in urban areas. Cities, 30, 18-30. doi:10.1016/j.cities.2011.11.002

Monzón, A., Ortega, E., \& López, E. (2016). Influence of the first/last mile on HSR accessibility levels. In K. T. Geurs, T. Dentihno, \& R. Patuelli (Eds.), Accessibility, equity and efficiency: Challenges for transport and public services (pp. 125-143). Aldershot: Edward Elgar.

Mota, C., López, M. A., \& Martínez-Rodrigo, A. (2017). A mathematical study of accessibility and cohesion degree in a high-speed rail station connected to an urban bus transport network. Open Physics, 15(1), 160. doi:10.1515/phys-2017-0017

Naranjo Gómez, J. (2016). Impacts on the social cohesion of mainland Spain's future motorway and high-speed rail networks. Sustainability, 8(7), 624. doi:10.3390/su8070624

Nash, C. (2015). When to invest in high speed rail. Journal of Rail Transport Planning \& Management, 5(1), 12-22. doi:10.1016/J.JRTPM.2015.02.001

Novak, D. C., \& Sullivan, J. L. (2014). A link-focused methodology for evaluating accessibility to emergency services. Decision Support Systems, 57, 309-319. doi:10.1016/j.dss.2013.09.015

Observatorio del Ferrocarril en España. (2017). Informe 2017. Fundación de los Ferrocarriles Españoles y Ministerio de Fomento, Madrid.

Ortega, E., López, E., \& Monzón, A. (2012). Territorial cohesion impacts of high-speed rail at different planning levels. Journal of Transport Geography, 24, 130-141. doi:10.1016/j.jtrangeo. 2011.10.008

Ortega, E., López, E., \& Monzón, A. (2014). Territorial cohesion impacts of high-speed rail under different zoning systems. Journal of Transport Geography, 34, 16-24. Retrieved from http://www. sciencedirect.com/science/article/pii/S0966692313002160

Ortega, E., Mancebo, S., \& Otero, I. (2011). Road and railway accessibility atlas of Spain. Journal of Maps, v2011, 31-41.

Ortega, E., Pastor, I., \& Mancebo, S. (2014). TITIM GIS-tool: A GIS-based decision support system for measuring the territorial impact of transport infrastructures. Expert Systems with Applications, 41, 7641-7652. doi:10.1016/j.eswa.2014.05.028

Páez, A., Scott, D. M., \& Morency, C. (2012). Measuring accessibility: Positive and normative implementations of various accessibility indicators. Journal of Transport Geography, 25, 141153. doi:10.1016/j.jtrangeo.2012.03.016

Peters, D. (2003). Cohesion, polycentricity, missing links and bottlenecks: Conflicting spatial storylines for pan-European transport investments. European Planning Studies, 11(3), 317-339. doi:10.1080/09654310303638

Preston, J. (2009). The case for high-speed rail: A review of recent evidence. Report 09/129. London: RAC Foundation.

Reggiani, A. (1998). Accessibility, trade and location behavior. Aldershot: Ashgate.

Reggiani, A. (2012). Accessibility, connectivity and resilience in complex networks. In K. Geurs, K. Krizek, \& A. Reggiani (Eds.), Accessibility analysis and transport planning (pp. 15-36). Chelttenham: Edward Elgar.

Sanders, L. J., Aguilar, G. D., \& Bacon, C. J. (2013). A spatial analysis of the geographic distribution of musculoskeletal and general practice healthcare clinics in Auckland, New Zealand. Applied Geography, 44, 69-78. doi:10.1016/j.apgeog.2013.07.014

Sparks, A. L., Bania, N., \& Leete, L. (2011). Comparative approaches to measuring food access in urban areas: The case of Portland, Oregon. Urban Studies, 48(8), 1715-1737. doi:10.1177/ 0042098010375994 
Talen, E., \& Anselin, L. (1998). Assessing spatial equity: An evaluation of measures of accessibility to public playgrounds. Environment and Planning A, 30(4), 595-613. Retrieved from http:// www.envplan.com/abstract.cgi?id=a300595

Ureña, J., Menerault, P., \& Garmendia, M. (2009). The high-speed rail challenge for big intermediate cities: A national, regional and local perspective. Cities, 26(5), 266-279. doi:10.1016/j.cities. 2009.07.001

van Wee, B., \& Geurs, K. T. (2011). Discussing equity and social exclusion in accessibility evaluations. EJTIR, 11(4), 350-367. Retrieved from http://doc.utwente.nl/78074/

Vickerman, R. (2015a). Can high-speed rail have a transformative effect on the economy? Transport Policy, 62, 31-37. doi:10.1016/j.tranpol.2017.03.008

Vickerman, R. (2015b). High-speed rail and regional development: The case of intermediate stations. Journal of Transport Geography, 42, 157-165. doi:10.1016/j.jtrangeo.2014.06.008

Vickerman, R., \& Ulied, A. (2009). Indirect and wider economic impacts of high speed rail. In G. de Rus (Ed.), Economic analysis of high speed rail in Europe (pp. 89-118). Madrid: Fundación BBVA.

Wan, N., Zhan, F. B., Zou, B., \& Chow, E. (2012). A relative spatial access assessment approach for analyzing potential spatial access to colorectal cancer services in Texas. Applied Geography, 32(2), 291-299. doi:10.1016/j.apgeog.2011.05.001

Wang, F. (2012). Measurement, optimization, and impact of health care accessibility: A methodological review. Annals of the Association of American Geographers. doi:10.1080/00045608.2012. 657146

Yang, D.-H., Goerge, R., \& Mullner, R. (2006). Comparing GIS-based methods of measuring spatial accessibility to health services. Journal of Medical Systems, 30(1), 23-32. doi:10.1007/s10916-0067400-5

Zhang, W., Nian, P., \& Lyu, G. (2016). A multimodal approach to assessing accessibility of a highspeed railway station. Journal of Transport Geography, 54, 91-101. doi:10.1016/j.jtrangeo.2016. 05.007 